\title{
Tourist Destination Integral Product Eco-Efficiency
}

Sandra Janković, Faculty of Tourism and Hospitality Management, Croatia Vanja Vejzagić, Faculty of Tourism and Hospitality Management, Croatia Dubravka Vlašić, Faculty of Tourism and Hospitality Management, Croatia

\begin{abstract}
The main objective of this article is to illustrate the accounting methodology for eco-efficiency measurement, which allows for inclusion of the economically-orientated component in the processes of environmental reporting on tourist destination integral product, while examining the interrelation of eco-costs and values found in the classic LCC and particular tourist destination SBU (Strategic Business Unit). The process of tourist destination integral product eco-efficiency measurement calls for development of environmental accounting methods suitable for presentation of economically-orientated sustainability information. In the complex process of integral product eco-efficiency measurement, LCA (Life Cycle Assessment) and LCC (Life Cycle Costing) take important roles. Interpretation and presentation of the data includes detailed cradle-to-grave environmental impact assessment of direct and indirect tourist activity and different products of tourist destination SBU's. Eco-costs represent the monetary component in the processes of environmental accounting and reporting on environmental impact of tourist destination integral product.
\end{abstract}

Keywords: Life Cycle Assessment; Life Cycle Costing; Environmental Accounting; Environmental Reporting; Eco-efficiency; Tourist Destination Integral Product

\section{INTRODUCTION}

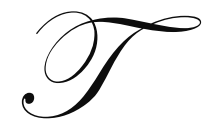

ourist destination is the basic unit of tourist supply. Its successful market presentation depends on its capability of turning comparative advantages into competitive ones. The business interaction of all integral product supply participants at the tourist destinations level can offer environmentally acceptable and economically useful products for all tourist participants and positive impact on the macroeconomic picture of the area, if principles of sustainable development are taken into account. Tourist destination management - if based on the principles of corporate governance and sustainable development - is responsible for successful synthesis of several basic tourist destination products into an integrated tourist destination product. Integrated tourist destination product creation and affirmation requires an adequate system of eco-reporting on the status, changes and impact of individual participants and products on the destination's eco-system, as part of the overall sustainable reporting system. The eco-reporting system - based on the specific integrative information system - enables the preparation of information on eco-efficiency of main processes, products and/or tourist destination systems throughout their entire life cycle.

\section{TOURIST DESTINATION INTEGRAL PRODUCT}

Tourist satisfaction depends on the level at which the tourist's needs and expectations are met and the level of quality of the tourist destination integral product. Tourist destination integral product is a result of cooperation of all supply participants (hotels, tourist agencies, local population, etc.) and their efforts put into tourist destination integral product development and market realization. Tourist destination integral product represents a coordinated synthesis of individual tourist supply interests into a uniquely recognized tourist product geared to meet the desires, requirements and capabilities of the tourist's demand. Characteristics of such product are correlated with the specific 
interests of participants involved in the process of tourist destination integral product design and the total level of available resources necessary for its formation.

In the process of integral product design, development and market realization emphasis is on the preservation of qualitative and quantitative characteristics of tourist destination, especially if the natural and environmental resources are recognized as fundamental motivations for tourist travel. Successful establishment of tourist destination integral product requires sound implementation of principles of sustainable development and "Total Quality Management" (TQM) philosophy. These are the main conditions for avoiding the negative effects of excessive commercialization of the tourist destination integral product and depletion of valuable resources - social, cultural, historical and ecological. This is where processes of tourist destination integral product life cycle planning and development should be taken into consideration, as they include implementation of rules, procedures and tools important for successful operationalization of concepts, with the aim for positive market values - desired by all stakeholders involved in the tourist destination business processes.

Tourist destination is a dynamically regulated system that evolves in space and time. It is necessary to predict and pre-specify adverse system reactions to various external and internal influences in order to successfully direct the development towards a positive end result. Influences include changes in preferences and needs of the tourists, the general level of tourists' disposable income, infrastructure and availability of tourist destinations, cultural and historical heritage offer, promotion and eco-systems protection, etc. All of these significantly influence the structure of aggregate demand, and it is therefore necessary to examine assumptions and possibilities of tourist destination integral product market valuation from economic, social and environmental points of view.

Negative effects of tourism on tourist destination eco-system are proportional with the tourist increase. In addition, negative environmental impacts are manifested as an increase in all types of waste, as a sanitary pressure on infrastructure, increased energy consumption and harmful emissions to air, water, soil, etc. Implementation of environmental policy in the tourist destination integral product approach requires application of relevant impact evaluation criteria based on the principles of sustainable development and a plan of corrective actions that can be implemented into tourist destination strategy by tourist destination management system. It is necessary to intervene in the existing business IT system by applying new instruments and methodologies for preparation of environmental impact and/or cost reports. The intervention includes transformation of the recorded data into useful information in compliance with environmental policy and principles of sustainable development. That information, orientated towards environmental and economic sustainability measurement and improvement in tourist destination, can be successfully represented in the form of eco-efficiency.

\section{ECO-EFFICIENCY}

The concept of eco-efficiency is the link between monetary and physical environmental management accounting for decision-making in a systematic manner. 'Eco-efficiency is achieved by the delivery of competitively-priced goods and services that satisfy human needs and bring quality of life, while progressively reducing ecological impacts and resource intensity throughout the life-cycle to a level at least in line with the earth's estimated carrying capacity' (Lheni, 2000: 4). Eco-efficiency represents production capability based on production input with low environmental impact, while reducing the overall quantity of the production input. As a result, overall costs, waste quantity and environmental impacts are lowered, thus establishing a sustainable interrelation between environmental and economical goals for the entire life cycle of a product, which can be measured using the eco-efficiency indicator. The World Business Council for sustainable Development (WBCSD) defines an ecoefficiency indicator as an indicator that relates "product or service value" in terms of turnover, or profit to "environmental influence" in terms of energy, materials and water consumption, as well as waste and emission in terms of volumes (IFAC, 2005: 41). 'An eco-efficiency indicator is the ratio between an environmental and a financial variable. It measures the environmental performance of an enterprise with respect to its financial performance' (Sturm et al, 2004: 1).

Life Cycle Costing (LCC)

Life Cycle Assessment (LCA) 
In quantified expression of eco-efficiency, the numerator represents the total value of costs over the entire life cycle of the product or production system. The denominator represents the naturally-expressed value of the impact on the environment of product or production system's life cycle. Calculation of single index eco-efficiency value of the integrated product of tourist destination at the micro and macro levels requires examination of the dynamics of business changes in a tourist destination. Each Strategic Business Unit (SBU) index represents ecoefficiency at the micro level as a part of the overall tourist destinations product supply, while at the macro level, index represents the normalized average of all distinct values of tourist destinations SBU's in relation to the level of environmental impact and total business activities of the tourism destinations (Figure 1).

The microeconomic approach to the calculation of tourist destination integral product eco-efficiency plays as an analytical instrument of sustainability for each business process, activity, subject or a whole life cycle of a tourist destination integral product. This shows indicative interrelationship between the economic and environmental components in the business. Macroeconomic concept of eco-efficiency - from a statistical standpoint - represents the overall value incurred at the micro level of acitivity. However, the management function recognizes the market interdependence in relationships, actions and actual business results at the micro-level of tourist destinations, realizing that dynamic complexity of macro level approach represents more than the sum of all values obtained at the micro level.

Overall eco-efficiency dependency of tourist destinations product should be considered analogous to "... the overall level of tourist satisfaction depends on the total level of the tourist destination product, which is a result of the synergic effect of all participants in the tourist product supply (not just the sum of the effects of all individual participants) and success in anticipation of tourist wishes for specific tourist product " (Senečić et al, 1997: 88). Characteristics of tourist destination products (simple, elementary or integral) are correlated with the interrelations of the market participants involved in the process of designing tourist products and the manner and level of use of total available tourist resources necessary for its formation.

Figure 1: Strategic Business Units (SBU's) in Tourist Destination

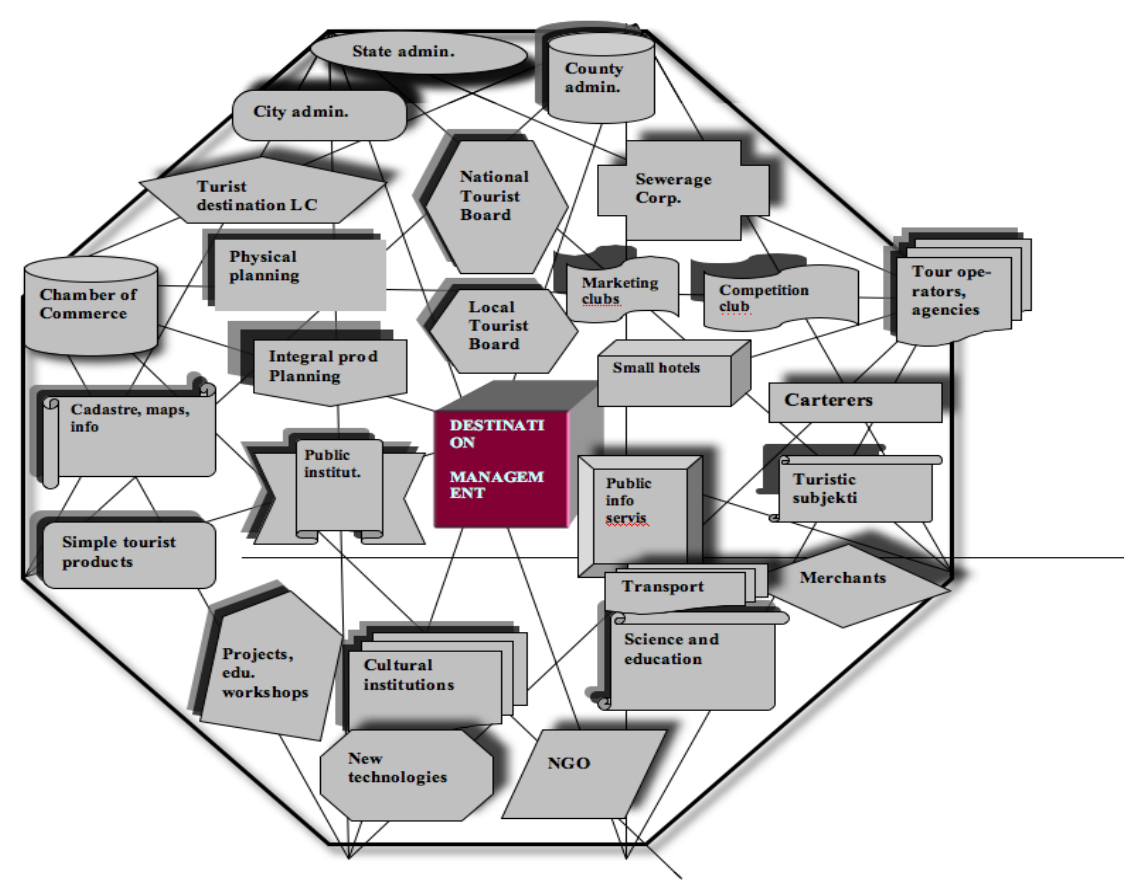

Source: (Blažević et Peršić, 2009: 184) 
The main objective of the process of integral tourism destination product eco-efficiency measurement and overall improvement is to establish a balanced and sustainable relationship between primary - natural beauty, cultural heritage, etc. - and secondary - accommodation, meals, recreation, etc.- tourist destination supply. Secondary tourist supply is a result of human efforts aimed to develop and improve access to primary supply in the tourist market. In its development, qualitative and quantitative characteristics of destinations should not be affected, especially if natural resources are recognized as the main characteristic of the eco-environment and the fundamental motivation for tourist visit.

The basis for improvement of eco-efficiency of activities attached to the integral product from the perspective of primary and secondary tourism destination supply, has to be sought through reduction of energy, water and use of natural materials, reduction of waste and pollution levels, extension of the functional life of the product, incorporation of life cycle principles, consideration of the usefulness and recyclability of products/services at the end of their useful life and increased service intensity. 'Eco-efficiency optimization is achieved through segmentation and analysis of every particular process in the life cycle of a product and concerned with three broad objectives' (Lehni, 2000: 5):

- Reducing the consumption of resources (minimizing the use of energy, materials, water and land, enhancing recyclability and product durability, closing material loops)

- $\quad$ Reducing the impact on nature (minimizing air emissions, water discharges, waste disposal and the dispersion of toxic substances, as well as fostering the sustainable use of renewable resources)

- Increasing product or service value (providing more benefits to customers through product functionality, flexibility and modularity, additional services and selling the functional needs that customers actually want. This raises the possibility of the customer receiving the same functional need with fewer materials and less resources)

Quantification of presented categories is conducted simultaneously through interrelation of economic and environmental impacts. While tourist destination LCA secures information significant for the understanding of environmental impacts of a product, LCC meets the needs for economic evaluation of technically presented information of products' life cycle performance.

\section{LCA and Tourist Destination Integral Product}

From the tourist destination integral product perspective, LCA represents its overall environmental impact value over a lifetime, emerging as both direct and indirect consequences of tourist activity and evaluated by means of a selected functional unit. LCA describes energy and materials input processes which are transformed into product - desired product or service - and non-product - emissions, waste, etc. - output processes through business decision-making processes.

Life Cycle Assessment (LCA) is a holistic tool used in evaluation and reporting on relevant environmental impacts of products. It is a systematic, formally and structurally consistent approach to evaluation of economical and ecological impacts on particular systems, projects, processes, products, and services. LCA represents quantitative and qualitative data integrity in assessment of environmental impacts caused by the use of energy, materials, emissions, etc. during the entire life cycle of a product of tourist destination - concept, design, manufacture, transport, distribution, consumption, recycling, and waste management. 'The LCA study is performed to assess whether a product or system meets certain environmental standards, or whether it is environmentally sounder than another product or system.' (Guine et al, 2004: 10).

LCA study is based on ISO 14040 and ISO 140441. In environmental accounting, ISO 14040 is important as it offers a standardized methodological framework and technical support required for preparation and presentation of reports on environmental impacts of a product for the duration of its entire life cycle. This allows for the real and potential environmental impact assessment, and furthermore, evaluation of each individual phase of the life cycle of a product (ISO, 2006: 2). The issue of LCA study construction is typically addressed through four individual, yet interrelated phases (Figure 2). 
Figure 2: Stages of LCA

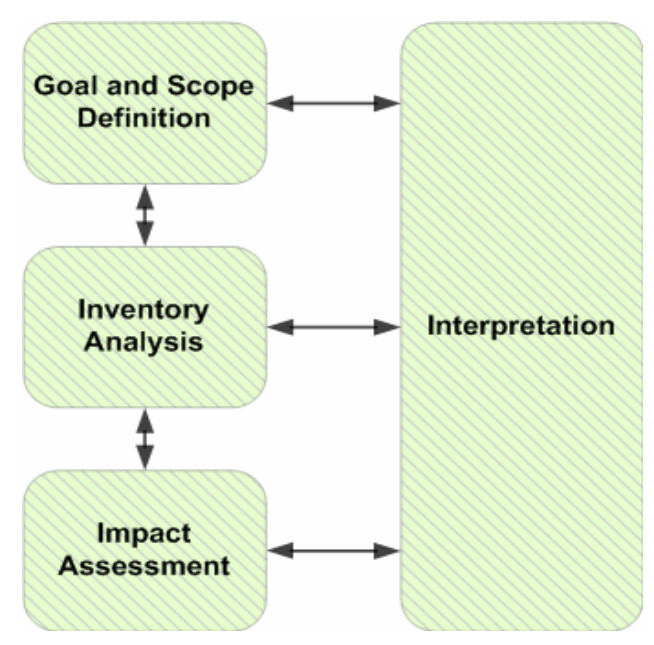

Source: (PRe Consultants, 2008: 24)

The success of a tourist destination LCA study relies on continuous study feedback; the most useful study data is reused and study phases reconstructed in order to improve each following, and also, preceding phase of the study. However, complete accuracy and methodological uniformity in environmental reporting is not possible as each LCA study requires clearly defined goals and system boundaries. Simultaneously, each LCA study requires clear interpretation of formulation, construction, and LCA element interrelation criteria. The total LCA of tourist destination integral product represents the total value of the environmental impact of all SBU expressed by the complementary defined objectives and scope of research, and thus uniquely defined functional unit.

\section{LCC and Tourist Destination Integral Product}

'Life cycle costing represents the total cost of ownership of machinery and equipment, including its cost of acquisition, operation, maintenance, conversion, and/or decommission' (Barringer et al, 2003: 2). LCC considers economical (monetary) effects of all the previous business activities in prediction of future business costs and risks, while considering all of the potential future economical flows. Product life cycle begins with extraction and production input processing, followed by phases of production, distribution, and finally, product consumption.

Processes of disassembly at the end of the product life cycle are evaluated from the production-related perspective only, which allows for the liability to be transferred from the consumer back to the manufacturer. LCC explores possibilities for minimization of capital investments and maintenance costs, while maximizing the profits so that in the structure of costing assets acquisition costs and assets maintenance costs are evaluated separately (Barringer et al, 2003: 5). The importance of LCC monitoring for integral product of tourist destination emerges from the fact that costs of operation, maintenance, and disposal exceed the initial procurement costs by up to 20 times (Barringer, 1996: 2). In other words, almost 65\% of all the future costs are determined in the design phase of the product life cycle (Barringer, 1996: 17).

'Life Cycle Cost means the amortized annual cost of a product, including capital costs, installation costs, operating costs, maintenance costs and disposal costs discounted over the lifetime of the product.' (Executive Order 1993, sec. 210). 'LCC value is discounted on net present value (NPV) that represents an economic standard method for evaluating competing long-term projects in capital budgeting. This measures the present worth of the multi-year investments' (Bhushan, Rai, 2004: 7) concerning assets depreciation, interest rate, taxes, etc., as follows: 


$$
\frac{R_{t}}{(1+i)^{t}}
$$

$\boldsymbol{t}$ - the time of the cash flow

$\boldsymbol{i}$ - the discount rate (the rate of return that could be earned on an investment in the financial

markets with similar risk.)

$\boldsymbol{R} \boldsymbol{t}$ - the net cash flow (the amount of cash, inflow minus outflow) at time $t$

Successful inclusion of all the relevant LCC determinants requires careful consideration of production, consumption, and waste management phases in the life cycle of a tourist destination product. This also allows for evaluation of the eco-costs value and their classification while considering source, time, and type of their origin (Table 1).

Table 1: Structure of Eco-costs

\begin{tabular}{|c|c|c|}
\hline \multicolumn{3}{|c|}{$\begin{array}{c}\text { Conventional costs } \\
\text { ital, Assets, Inputs, Stock, Utility, Investment...) }\end{array}$} \\
\hline \multicolumn{3}{|c|}{ Potentially hidden cost } \\
\hline \multirow{2}{*}{$\begin{array}{l}\text { Usual (planning, training, examination, } \\
\text { data collection, monitoring, testing, } \\
\text { modelling, corrections, recording, marking, } \\
\text { insurance, taxes, management fees...) }\end{array}$} & $\begin{array}{l}\text { Anticipative }(\mathrm{R} \& \mathrm{D}, \text { testing } \\
\text { permits, location preparation, } \\
\text { permits, engineering ...) }\end{array}$ & $\begin{array}{l}\text { Consequent (cessation or closure, } \\
\text { equipment destruction, area protection..) }\end{array}$ \\
\hline & \multicolumn{2}{|c|}{ Voluntary (feasibility study, recycling, protection, public relations, testing...) } \\
\hline \multicolumn{3}{|c|}{ Unpredictable costs } \\
\hline \multicolumn{3}{|c|}{$\begin{array}{l}\text { The costs of adaptation to future requirements; penalisation; penalties; future damage liability; improvement measures; } \\
\text { potential national resource damage, loss of property, impairment of personal rights etc. legal expenses ... }\end{array}$} \\
\hline \multicolumn{3}{|c|}{ Image costs and interest groups relations costs } \\
\hline \multicolumn{3}{|c|}{$\begin{array}{l}\text { Corporation image costs. PR cost, investors, insurers, management structures, employees, suppliers, lenders, the community, } \\
\text { the legislature .... }\end{array}$} \\
\hline
\end{tabular}

Source: (EPA,1995:9)

'Environmental costs are the costs of the environmental degradation that cannot be easily measured or remedied, are difficult to value, and are not subject to legal liability' (EPA, 2009: 1). A small proportion of ecocosts is classified as conventional in their origin, while the remaining proportion is often classified as hidden. According to the accounting theory, taking and/or ignoring an action in the future often creates a possibility for cost occurrence, which is why this type of eco-costs are classified as unpredictable.

The emergence of potential costs and future business risks demands for additional integration of the unpredictability factor into the accounting systems, procedures, and environmental reporting. However, the inclusion of all eco-costs is problematic due to the costs' unpredictability factor, with costs increasing from conventional to unpredictable, and with the image costs category characterized as the most unpredictable, and therefore most difficult to measure, quantify and evaluate. Opportunity for the overall eco-cost reduction - as one of the goals of eco-efficiency - lies in the ongoing effort for the current and future environmental costs reduction, capital costs reduction, market share increase, market position improvements and protection, and improved public relations.

\section{MODEL OF ECO-EFFICIENCY USING AHP}

Eco-efficiency information stimulates establishment of operational control, eco-program maintenance, and constant evaluation of tourist destination integral product eco-results within the tourist destinations business policies, set goals and tasks, while seeking ways for potential improvements. It influences the introduction of management processes for evaluation, control and audit of the environmental management system and search capabilities for the improvement of eco-systems and the results of all SBUs at the tourist destination level. Also, establishing and maintaining adequate levels of communication among participants in a system of internal and 
external customers will be stimulated as encouraging other market participants to establish an EMS - Environmental Management System.

Literature covering the areas of sustainable development stresses the need to ensure information basis for environmental management and to measure eco-efficiency, but does not single out any specific resources needed to provide timely information on monetary and non-monetary values of environmental impacts. Application of the instruments by which to generate information for EMS is a prerequisite for successful decision-making. Bennett (Bennett et al, 2002) emphasizes the thesis that it is necessary to ensure generation, selection, evaluation and use of financial and non-financial information to optimize the ecological and economic business corporations and business to achieve sustainability.

The requirement for an integral information system, as the basis of business decision-making, demands for elimination of the difference between the measuring units - monetary LCC and natural LCA. Due to this, application of the Analytical Hierarchy Process method (AHP) is recommended in order to improve the existing models which are not able to provide simple solution implementation for complex decision-making processes (Bhushan, Rai, 2004: 15). AHP method helps the decision-maker in solving complex problems, respecting its structure and organization (setting criteria hierarchy problem) while considering, measuring and synthesising final results. 'AHP is a method for ranking decision alternatives and selecting the best one given multiple criteria' (Taylor, 2006: 404).

Figure 3: Eco-efficiency Model of Tourist Destination Integral Product

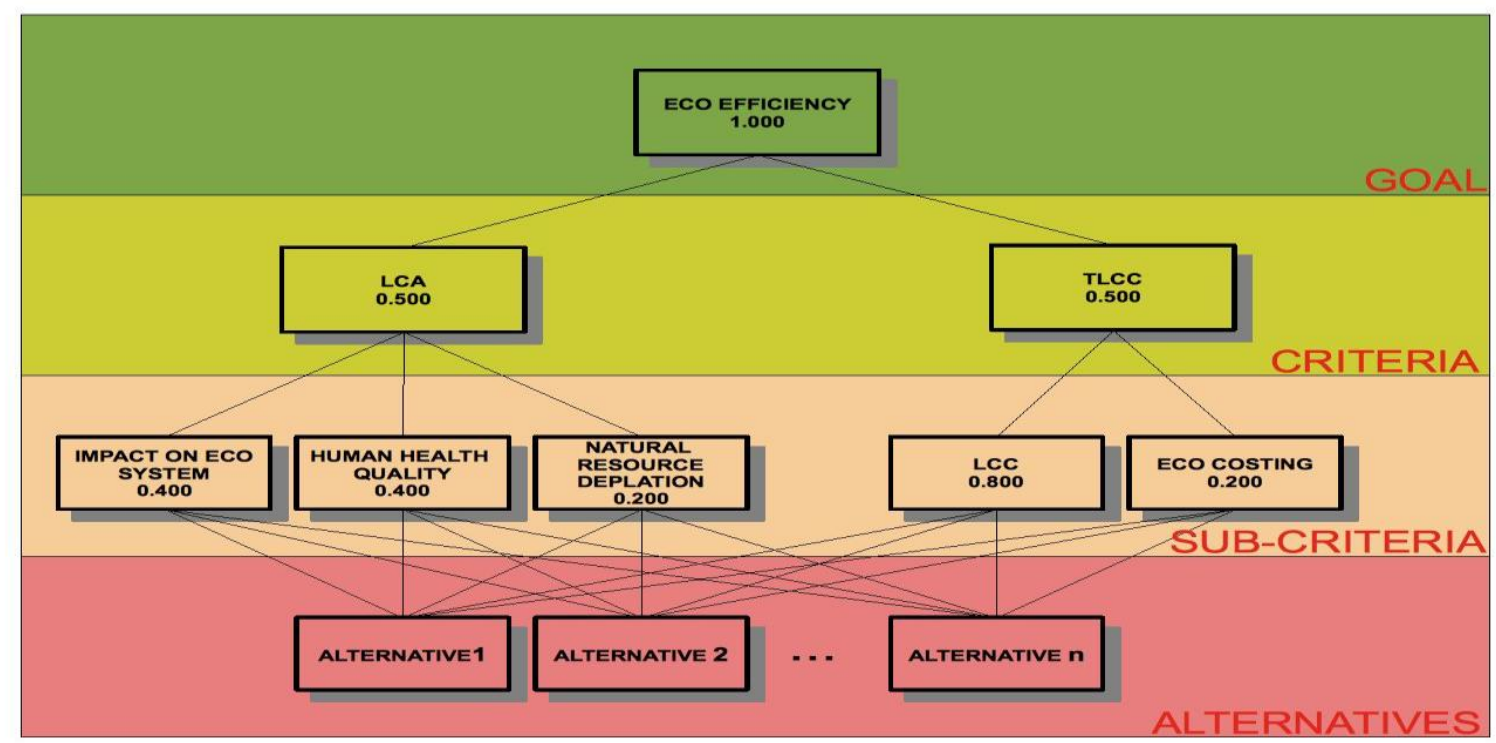

Source: Author; based on (Barringer et al, 2003; EPA,1995; Emblemsvag, 2003; Guine at al, 2004;ISO, 2006; Peršić et al, 2006;; Taylor, 2006)

The tourist destination information system is complex and requires to be designed as a network so that each segment of tourist destinations supply could assume a role of a strategic business unit - SBU, and for whom the information system should provide relevant information. The main objective of an integrated information system is to meet the requirements for securing information needs of individual participants in the supply structure of the integrated product of tourist destination.

AHP method opens the possibility of result observation through system interrelations, in which the pairs of alternatives are observed in correspondence with the criteria set, evaluated between them and ranked according to the level of impact on the end result. From the criterion impact intensity assessment, a preference scale assigns the compared alternatives with numeric values to different levels of preference (Taylor, 2006: 406) in the matrix form. 
AHP method is selected as it offers the possibility of LCC and LCA model information modification - relativization - so that the overall value of environmental impact and the overall cost of the tourist destination product life cycle could be converted into an unitary value, which would then represent the degree of eco-efficiency. The basis of the LCA and LCC integration by AHP method application stems from the need to retain all the analytical advantages that both models offer in research and result presentation, while improving the existing integrative information system (Figure 3).

Through paired comparison of criteria (LCA and LCC), sub-criteria, and the product, and by application of the AHP method, the degree of eco-efficiency of a product and its selected alternatives is calculated. The results of the three LCA sub-criteria (EQ - eco-system quality $=40 \%$; HH - human health $=40 \% ; \mathrm{R}$ - natural resources $=20 \%$ ) (PRe, 2008; 23) are linked to the results of the two LCC model sub-criteria (LCC - life cycle costing=80\%; EC eco-costs $=20 \%$ ). Based on the thesis by which the goal of eco-efficiency is to establish a balanced interrelation between environmental and economic objectives of sustainable development, the impact of the LCA and LCC criteria on the model result is assessed at 0.5 for each of the criteria.

The first sub-criterion represents the classical approach to LCC which determines the current NVP of the project. The second sub-criterion represents life cycle eco-costs inherent to LCA, assessed and accepted as the arithmetic mean of the relative share of empirically identified regularity, which amounts to $15-25 \%$, depending on the nature of business activity (DeSimone et Popoff, 2000: 26 -28). The calculation of relative values by which the alternatives impact on each of the five criteria, and calculation of relative share of the value of the criteria which affect the level of eco-efficiency, is enabled by derivation of formula that represents the overall relative ecoefficiency levels for each of the products in the model, and thus:

$$
\begin{aligned}
\mathbf{P}_{(\mathrm{EE})}= & \mathbf{P}_{(\mathrm{EE} 1)}+\mathbf{P}_{(\mathrm{EE} 2)}=0,2 \mathrm{P}_{\mathrm{eq}}+0,2 \mathrm{P}_{\mathrm{hh}}+0,1 \mathrm{P}_{\mathrm{r}}+0,4 \mathrm{P}_{\mathrm{lcc}}+0,1 \mathrm{P}_{\mathrm{ec}} \\
\mathbf{A 1}_{(\mathrm{EE})}= & \mathbf{A} \mathbf{1}_{(\mathrm{EE} 1)}+\mathbf{A} \mathbf{1}_{(\mathrm{EE} 2)}=0,2 \mathrm{~A} 1_{\mathrm{eq}}+0,2 \mathrm{~A} 1_{\mathrm{hh}}+0,1 \mathrm{~A} 1_{\mathrm{r}}+0,4 \mathrm{~A} 1_{\mathrm{lcc}}+0,1 \mathrm{~A} 1_{\mathrm{ec}} \\
& \quad \ldots \\
\mathbf{A n} & \mathbf{n}_{(\mathrm{EE})}=\mathbf{A} \mathbf{n}_{(\mathrm{EE} 1)}+\mathbf{A} \mathbf{n}_{(\mathrm{EE} 2)}=0,2 \mathrm{An}_{\mathrm{eq}}+0,2 \mathrm{An}_{\mathrm{hh}}+0,1 \mathrm{An}_{\mathrm{r}}+0,4 \mathrm{An}_{\mathrm{lcc}}+0,1 \mathrm{An}_{\mathrm{ec}}
\end{aligned}
$$

In equations (4 and 5), $\mathrm{P}(\mathrm{EE})$ represents the overall relative level of eco-efficiency of products compared to the alternatives (A1 (EE) - an (EE) in the model, which is calculated from the sum of relative share of the criteria $(\mathrm{P}(\mathrm{EE} 1)+\mathrm{P}(\mathrm{EE} 2))$. The total relative value of criteria is to the sum of all the relative sub-criteria value. Condition for the validity of the statements in the equation, which says that the sum of all the relative share of the ecoefficiency is equal to 1 , is as follows:

$\mathrm{P}(\mathrm{EE})+\mathrm{A} 1(\mathrm{EE})+\ldots+\mathrm{An}(\mathrm{EE})=1$

Depending on the structure and purpose of research, the best option for a final decision can be chosen at the decision-making level, based on ranked values of eco-efficiency, and with the option to change the level of preference criteria or level of criteria itself.

\section{CONCLUSION}

The ultimate SBU objective at a tourist destination level is to improve its relationship with the environment and to improve the welfare of local population by using the appropriate eco-efficiency parameter estimates. Lack of standardized methods for monitoring, recording and reporting on environmental impacts and costs caused by activities in a tourist destination implies the need to join the environmental and economic aspects of business. To eliminate some disadvantages of LCA and LCC methods, application of the AHP (Analytic Hierarchy Process) method maintains both the consistency and quality of presentation of tourist destination's integral product ecoefficiency information as a qualitative contribution to the process. 


\section{AUTHOR INFORMATION}

Sandra Janković, Ph.D.: Current Position: Associate Professor at Faculty of Tourism and Hospitality Management, University of Rijeka (Undergraduate, Graduate and Ph.D. Study) and Vice-Dean for International Cooperation. Teaches Management Accounting, Financial Accounting, International Accounting, Accounting for Small and Medium Enterprises and Auditing. Graduate and postgraduate researches mentor and co-mentor. Education: Ph.D. in 2001, Doctoral program Vienna University of Economics and Business Administration; Master of Science in 1997, Faculty of Tourism and Hospitality Management Opatija. Research Interest: Cost Accounting and Cost Management in Hospitality Industry, Environmental Management Accounting in Hospitality Industry, Revenue Management in Service Industry.

Vanja Vejzagić M.Sc.: Current Position: Research Assistant at Faculty of Tourism and Hospitality Management, University of Rijeka. Education: Ph.D. study (in progress), Doctoral program Faculty of Tourism and Hospitality Management Opatija and research at Manchester Metropolitan University; MSc. Master of Science in 2009, Faculty of Tourism and Hospitality Management Opatija. Research Interest: Environmental Management Accounting in Hospitality Industry, Strategic Management Accounting, Cost Accounting and Cost Management in Hospitality Industry.

Dubravka Vlašić, M.Sc.: Current Position: Assistant at Faculty of Tourism and Hospitality Management Opatija, University of Rijeka (Undergraduate, Graduate). Assists in teaching Accounting and auditing courses. Education: M.Sc. in 2005, Master of Science in 2005, Faculty of Tourism and Hospitality Management Opatija. Research Interest: Financial Accounting in Hospitality Industry, Environmental Management Accounting in Hospitality Industry, Environmental Auditing and internal auditing in hospitality industry.

\section{REFERENCES}

1. Barringer, H.P., Barringer, P.E. \& Associates, Inc. (2003). A Life Cycle Cost Summary. ICOMS.

2. $\quad$ Barringer, H.P., Weber, D.P. (1996). Life Cycle Cost Tutorial.

3. Bhushan, N., Rai, K. (2004). Strategic Decision-making. Springer Ltd.

4. $\quad$ Bloch, H.P. (1998). Practical Machinery Management for Process Plants: Vol. 1: Improving Machinery Reliability. $3^{\text {rd }}$ ed. Houston: Gulf Professional Publishing.

5. Cooper, R. (1990). Explicating the Logic of ABC. UK: Management Accounting.

6. DeSimone, L. \& Popoff, F. (2000). Eco Efficiency: The Business Link to Sustainable Development. Cambridge: MIT Press.

7. Emblemsvag, J. (2003). Life Cycle Costing: Using Activity-Based Costing and Monte Carlo Methods to Manage Future Costs and Risks. New Jersey: John Wiley \& Sons Inc.

8. Environmental Protection Agency (1995). Environmental Accounting Project: An Intoduction to Environmental Accounting as a Business Management Tool: Key Concepts and Terms. US: ICF Inc.

9. Environmental Protection Agency (2008). Types of Costs.

10. http://www.epa.gov/osw/conserve/tools/fca/costs.htm (Pretraženo 6. Veljače 2009.)

11. Executive Order (1993). "Federal Acquisition, Recycling, and Waste Prevention". In: Executive Order 12873. Section 210.

12. The Federal Facilities Council (2001). A Guide to Integrating Value Engineering, Life Cycle Costing, and Sustainable Development. Technical Report No. 142. Washington D.C.: National Academy Press.

13. Guine, J.B., Gorre, M., Heijungs, R., Huppes, G., Kleijn, R., Koning, A., Oers, L., Sleeswijk, A.W., Suh, S., Helias, A., Haes, U., Bruijn, H., Duin, R., Huijbregts, M.A.J. (2004). Handbook on Life Cycle Assessment: Operational Guide to the ISO Standards. Dordrecht: Kluwer Academic Publisher.

14. Horngren, C.T., Srikant, D.M., Foster, G. (2002). Cost Accounting: A Managerial Emphasis. California: Prentice Hall.

15. IFAC (2005), International Guidance document, Environmental Management Accounting, International federation of Accountants,

16. ISO 14040 (2004). Environmental Management: Life Cycle Assessment: Principles and Framework.

17. ISO 14044 (2006). Environmental Management: Life Cycle Assessment: Requirements and Guidelines. 
18. Kumaran, D.S., Ong, K.S., Tan, R.B.H., Nee, A.Y.C. (2000). Environmental Life Cycle Cost Analysis. Proceedings of the 2000 InLCA Conference held in Washington D.C.

19. Lehni, M. (2000). Eco-Efficiency: Creating More Value with Less Impact. North Yorkshire: WBSCD.

20. Lyrstedt, F. (2005). Measuring Eco-Efficiency by a LCC/LCA Ratio: An Evaluation of its Applicabilty. Goteborg: Chalmers University of Technology.

21. Peršić, M., Janković, S. (2006). Menadžersko računovodstvo hotela. Zagreb: Hrvatska zajednica računovođa I financijskih djelatnika.

22. PRe Consultants (2008). Introduction to LCA with SimaPro 7. Amsterdam.

23. Saltelli, A., Ratto, M., Andres, T., Campolongo, F., Cariboni, J., Gatelli, D., Saisana, M. \& Tarantola, S. (2008). Global Sensitivity Analysis. The Primer. New Jersey: John Wiley \& Sons Inc.

24. Senečić, J., Vukonić, B., (1997), Marketing u turizmu, Mikrorad d.o.o., Zagreb

25. Sturm, A., Mueller, K. \& Upasena, S. (2004). A Manual for the Preparers and Users of Eco-Efficiency Indicators. Proceedings of the 2004 United Nations Conference on trade and development. New York: United Nations Publications.

26. Taylor, B.W. (2006). Introduction to Management Science. $9^{\text {th }}$ ed. New Jersey: Prentice Hall.

27. United Nations (1987). Report of the World Commission on Environment and Development. General Assembly Resolution 42/187.

28. United Nations (2001). Environmental Management Accounting Procedures and Principles. NY. 